ARTICLE OPEN

\title{
The role of titanium in the initiation of localized corrosion of stainless steel 444
}

\author{
Samantha Michelle Gateman ${ }^{1}$, Lisa Irene Stephens ${ }^{1}$, Samuel Charles Perry ${ }^{1}$, Robert Lacasse ${ }^{2}$, Robert Schulz ${ }^{2}$ and Janine Mauzeroll ${ }^{1}$
}

Titanium has been added to ferritic stainless steels to combat the detrimental effects of intergranular corrosion. While this has proven to be a successful strategy, we have found that the resulting Ti-rich inclusions present on the surface play a significant role in the initiation of other forms of localized corrosion. Herein, we report the effect of these inclusions on the localized corrosion of a stainless steel using macro and micro electrochemical techniques. Through the use of scanning electrochemical microscopy, we observe the microgalvanic couple formed between the conductive inclusions and passivated metal matrix. The difference in local reactivity across the material's surface was quantified using a 3D finite element model specifically built to respect the geometry of the corrosion-initiating features. Combined with electron microscopy and micro elemental analysis, localization of other alloying elements has been reported to provide new insight on their significance in localized corrosion resistance.

npj Materials Degradation (2018)2:5 ; doi:10.1038/s41529-018-0026-5

\section{INTRODUCTION}

Owing to their cost effectiveness, ${ }^{1}$ austenitic stainless steels (SS) are often replaced with ferritic SS containing low amounts of $\mathrm{Ni}$. However, ferritic $\mathrm{Fe}-\mathrm{Cr}$ alloys are susceptible to intergranular corrosion (IGC), which greatly decreases the material's lifespan. In SS, this tends to occur along grain boundaries at the $\mathrm{Cr}$-depleted zones that form adjacent to chromium carbide precipitates. ${ }^{2}$ IGC can be minimized by limiting the amount of $\mathrm{C}$ and $\mathrm{N}$ within the alloy, specific heat treatments, and by alloying the metal with stabilizing agents such as $\mathrm{Ti}$ and $\mathrm{Nb}$. These elements have higher chemical affinities to $\mathrm{C}$ and $\mathrm{N}$ than $\mathrm{Cr}$ does and so will preferentially precipitate, leaving the $\mathrm{Cr}$ in solid solution. This allows for the formation of protective $\mathrm{Cr}$ oxides, ultimately increasing the material's resistance to IGC. ${ }^{3-5}$ Despite the successful reduction of IGC in alloyed ferritic SS, its mechanical strength can still be greatly reduced by pitting corrosion, usually associated with some discontinuity over the metal surface, such as a grain boundary, a defect/scratch, or an inclusion within the metal's microstructure. ${ }^{6}$

Among the typical corrosion initiators, manganese sulfide (MnS) inclusions in austenitic SSs have been identified as pitting corrosion initiation sites and have been extensively investigated using macro-scale $e^{7-10}$ and micro-scale ${ }^{11,12}$ techniques. More recently, $\mathrm{Ti}$ and $\mathrm{Nb}$ rich carbide and nitride inclusions have been found in SS resulting from the preferential precipitation of stabilizing agents, as previously described. ${ }^{4,13}$ Unlike the MnS inclusions found on austenitic $\mathrm{SS}, \mathrm{Ti}$ and $\mathrm{Nb} \mathrm{C} / \mathrm{N}$ inclusions are inherently electrochemically stable. ${ }^{14}$ The micron-sized inclusions have been reported to be involved in the initiation of corrosion fatigue $^{15}$ and stress corrosion cracking ${ }^{16}$ in a Ti stabilized Ni alloy, $690 T$ T. Previous works have suggested that the initiation of mechanical failure of Ti stabilized metals was associated to these inclusions by one of three possible mechanisms: (1) the preferential dissolution of the oxide nucleation core within the inclusions exposing active metal, ${ }^{16,17}$ (2) microvoids formed from large inclusions being broken during mechanical preparation of the metal, ${ }^{16}$ and (3) the enhancement of the surrounding metal matrix's electrochemical activity due to plastic strain, forcing it to act as an anode and therefore preferentially dissolving in high temperature water. $^{15}$ Despite all the mechanisms described above, the inclusion's electrochemical reactivity with respect to the surrounding metal matrix has not been reported or explored as a reason for the materials reported degradation mechanism in aqueous environments.

Comparing the alloyed SSs available today, SS 444 is an excellent candidate for a replacement material of expensive austenitic metals such as $316 \mathrm{~L}$ and $304 \mathrm{~L}$ due to its lower susceptibility to pitting corrosion. ${ }^{18}$ Although in many studies the microstructure of the material was characterized using scanning electron microscopy (SEM) and X-ray energy dispersive spectroscopy (XEDS), little attention was given to the heterogeneous microstructure's effect on localized corrosion. ${ }^{19,20}$ In order to investigate the material's polarization behavior on the micro-scale, the micro-droplet cell technique has been performed over Ti-stabilized ferritic SS materials to investigate the relationship between their microstructures and pitting potentials. ${ }^{17,19}$ No evidence was found to link the inclusions reported to localized corrosion, as the material did not undergo pitting corrosion, despite the previous reports of such inclusions instigating localized attack in other Ti stabilized alloys.

In this work, we have linked the Ti-rich inclusions found in highperformance SS 444 to initiating localized corrosion. This is done through the accelerated corrosion of SS 444 in a corrosive environment followed by material characterization using both macro and micro-scale electrochemical techniques; namely potentiodynamic polarization (PDP) measurements and scanning electrochemical microscopy (SECM). The material is studied ex situ via SEM/EDX analysis after accelerated corrosion to observe the

\footnotetext{
'Laboratory for Electrochemical Reactive Imaging and Detection of Biological Systems, McGill University, Montreal, QC H3A OB8, Canada and ${ }^{2}$ Institut de recherche d'HydroQuebec, Varennes, QC J3X 1S1, Canada

Correspondence: Janine Mauzeroll (Janine.mauzeroll@mcgill.ca)
}

Received: 4 October 2017 Revised: 22 December 2017 Accepted: 2 January 2018

Published online: 14 February 2018 
stability of the inclusions and understand their role in the initiation of localized corrosion. Elemental analysis of the secondary phase surrounding these inclusions also provides insight into the role of corrosion resistant alloying elements. The heterogeneous reactivity of the SS 444 was investigated using SECM in feedback mode to probe the local kinetic rate constants of a known redox mediator using a carbon fiber microelectrode (C-ME). Our specifically developed 3D finite element simulation was used to quantify the relative reactivity of cubic inclusions in a passive matrix, which represents a significant advance over existing axisymmetric models.

\section{RESULTS}

Microstructure characterization of SS 444

The microstructure of SS 444 consists of ferritic grains ranging from $40-70 \mu \mathrm{m}$ in diameter with heterogeneous inclusions randomly dispersed (Fig. 1a). These features were observed in as-received samples prior to any surface preparation (SI Figure S5). The inclusions have a cubic geometry ranging from $5-10 \mu \mathrm{m}$ in diameter. A series of EDX line scans revealed the composition of these inclusions to be mainly titanium, niobium and nitrogen (Fig. $1 \mathrm{~b} / \mathrm{d}, \mathrm{c} / \mathrm{e})$, with most inclusions being $\mathrm{TiN}$, in agreement with previous studies on SS $444 .^{13,15,19}$ The mean ratio of Ti to $\mathrm{N}$ was calculated as a mole percentage to be 1:0.96 using 5 EDX point analysis from five different inclusions.

The formation of a secondary phase rich in $\mathrm{Nb}$ was observed around the edges of the Ti-rich inclusions, indicating the segregation of $\mathrm{Nb}$ and $\mathrm{Ti}$. A high resolution image of an inclusion (Fig. 1a inset) reveals a cubic core of different elemental composition. Using both EDX linescans (Fig. 1c/e) and point analysis, this was found to be rich in $\mathrm{MgO}$ and $\mathrm{Al}_{2} \mathrm{O}_{3}$ (SI Figure S6); common nucleation sites reported for Ti-stabilized metals, ${ }^{4,15}$ with Al concentrations reported of $0.026 \mathrm{wt} \%$. Notably, not all inclusions possessed an oxide core as seen in the EDX linescan examples of pure and nucleated TiN inclusions in Fig. 1b/d, c/e, respectively, which is in agreement with thermodynamic calculations that confirmed pure TiN inclusions can form in the presence of sufficient concentrations of $\mathrm{Ti}$ and $\mathrm{N},{ }^{4}$ where similar metals have reported $\mathrm{N}$ concentrations as high as $0.04 \% .{ }^{19,20}$

Investigating bulk corrosion behavior

After accelerated corrosion via PDP measurements and extended immersion times of 1 week in $3.5 \mathrm{wt} \% \mathrm{NaCl}$, the early stages of micro-crevice corrosion were observed at the interface between the inclusions and bulk metal matrix (Fig. 2a). In order to investigate this phenomenon in more detail, the corrosion of the material was accelerated using electrochemical and chemical methods.

Considering the complexity of the alloy, several different reactions can contribute to the currents measured in the anodic branch all of which can be considered metal dissolution:

$\mathrm{M}_{(\mathrm{aq})}^{\mathrm{n}+}+\mathrm{ne}^{-} \rightleftarrows \mathrm{M}_{(\mathrm{s})}$

Due to the high weight percentage of Fe in the alloy, the anodic dissolution of Fe is likely to be the dominant contribution. To balance metal dissolution, two primary cathodic reactions can occur depending on the concentration of hydrogen ions in solution. At high concentrations, or low $\mathrm{pH}$, the main cathodic reaction is hydrogen evolution:

$2 \mathrm{H}_{(\mathrm{aq})}^{+}+2 \mathrm{e}^{-} \rightleftarrows \mathrm{H}_{2(\mathrm{~g})}$

Under neutral and aerated conditions, the cathodic reaction is mainly oxygen reduction:

$\mathrm{O}_{2(\mathrm{~g})}+2 \mathrm{H}_{2} \mathrm{O}_{(\mathrm{aq})}+4 \mathrm{e}^{-} \rightleftarrows 4 \mathrm{OH}_{(\mathrm{aq})}^{-}$

These and other corrosion reactions can be probed using PDPs, which allow for easy extraction of corrosion parameters such as the corrosion potential $\left(E_{\text {corr }}\right)$ and current density $\left(j_{\text {corr }}\right)$, as demonstrated in SI Figure S2. With $\mathrm{Fe}-\mathrm{Cr}$ alloys, spontaneous passive film formation causes a stable plateau in the anodic branch, known as the limiting current, or $j_{\text {lim. }}{ }^{21}$ This can be attributed to oxide formation and compression of the diffusion layer within the physical passive film, resulting in a steep concentration gradient perpendicular to the corroding surface hindering further dissolution of the metal. ${ }^{22,23}$ For SS $444, E_{\text {corr }}$ and $j_{\text {lim }}$ were measured to be $-0.12 \pm 0.01 \mathrm{~V}$ vs. saturated calomel electrode (SCE) and $0.5 \pm 0.02 \mu \mathrm{A} / \mathrm{cm}^{2}$, respectively. At potentials above this passive region, the log of the current increases linearly, which signals the onset of the transpassive region. The surface of the polarized samples was investigated using SEM/EDX analysis and revealed little to no indication of localized corrosion.

The goal of this work was to understand the role of Ti-rich inclusions in the mechanism of localized corrosion for metals alloyed with such stabilizing agents. Probing the corrosion behavior of SS is inherently difficult due to the spontaneous formation of a protective passive film significantly reducing its corrosion rate. Therefore, in order to promote localized corrosion of the ideal model material SS 444, the surface depassivation was attempted using two methods: first, through electrochemical reduction prior to the measurement; second, through the use of an aggressive etching solution during the measurement. This allowed for the observation of the corrosion behavior of the metal substrate through voltammetry, SEM, and EDX analysis of the corroded surface.
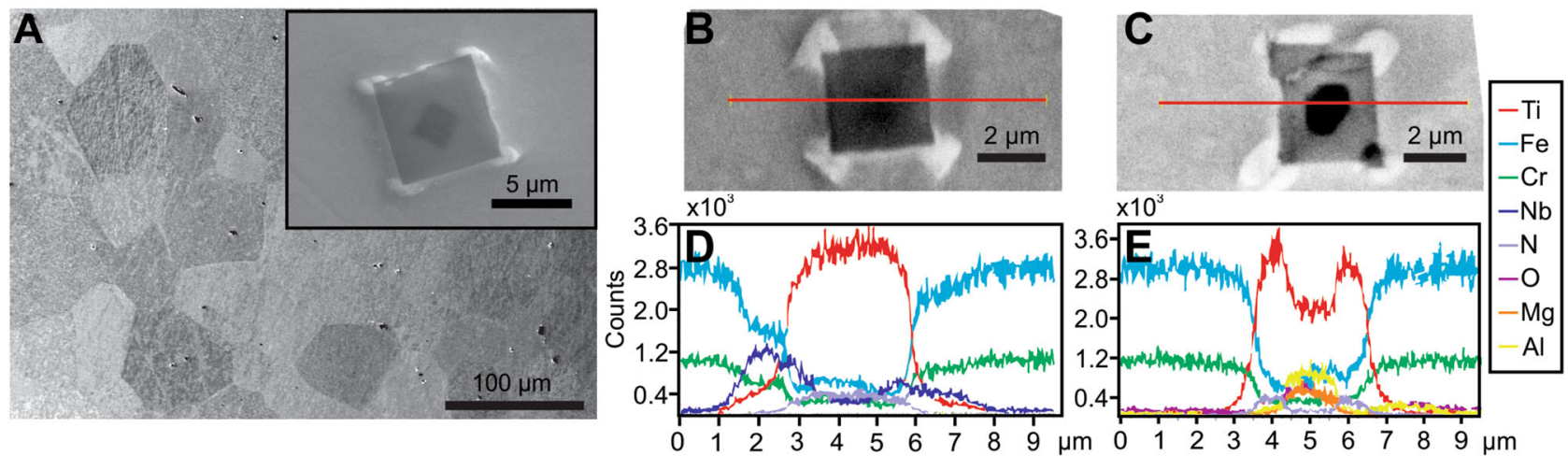

Fig. 1 a SEM of microstructure of polished SS 444 bulk sheet metal, showing polycrystalline ferritic grain decorated with Ti-rich inclusions. Inset shows a high-resolution SEM image of an inclusion. SEM image of a pure TiN inclusion of (b) an oxide-nucleated inclusion (c) with corresponding EDX lines scans, $\mathbf{d}$ and e, respectively, indicating local richness of $\mathrm{Nb}$ 

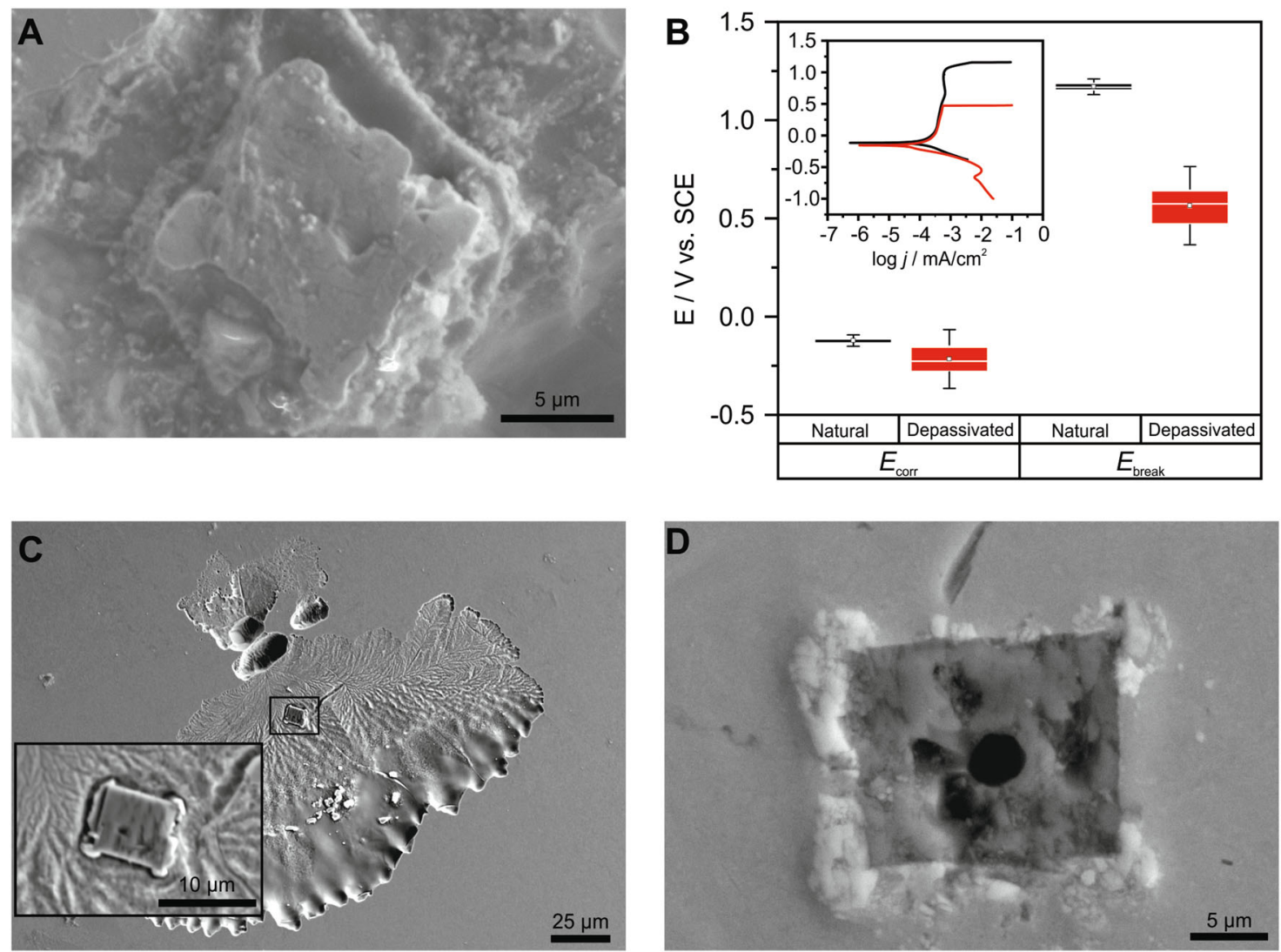

Fig. 2 a Micro crevice corrosion occurring at the interface between an inclusion and the metal matrix after PDP testing and 1 week immersion in $3.5 \mathrm{wt} \% \mathrm{NaCl}$. b Box plots of corrosion potential and potential breakdown values extracted from PDP measurements of passivated and electrochemically depassivated SS samples ( $n=3$, error bars represent absolute error at 95\% C.I.). (Inset) Examples of typical PDP measurements recorded for prepared SS 444 substrates. The naturally passivated sample (black curve) shows robust corrosion resistance by reaching the transpassive region while the depassivated and mechanically grown film (red curve) showed premature pitting. SEM images of (c) the micro leaf-like corrosion observed ex situ polarization of the depassivated sample. The inset shows the TiN inclusion directly in the center of the localized corrosion. d A stable oxide nucleated inclusion ex situ polarization

Inducing localized corrosion via electrochemical depassivation. In order to investigate localized corrosion, a reductive potential $(-1 \mathrm{~V}$ vs. SCE) was applied for 5 min prior to the PDP measurement in order to disrupt the passive film, and achieve some degree of depassivation. The $E_{\text {corr }}$ and $j_{\text {lim }}$ from the PDP measurement (Fig. $2 B$ inset) did not change significantly for the depassivated samples as values of $-0.20 \pm 0.03 \mathrm{~V}$ vs. SCE and $0.5 \pm 0.03 \mu \mathrm{A} / \mathrm{cm}^{2}$ were obtained respectively, either indicating the speed at which the protective layer forms during the PDP measurement or that the samples did not achieve full depassivation. Nonetheless, the material demonstrated a sharp increase in current density around $\sim 0.5 \mathrm{~V}$ vs. SCE, premature to the transpassive region previously measured for a naturally passivated sample. This decrease in breakdown potential was shown to be statistically different between the two samples, whereas their corrosion potentials were proven to be indifferent (Fig. 2b). This sudden increase in dissolution rate corresponds to the formation of a stable pit at the so called pitting potential, $E_{\text {pit, }}{ }^{24}$ which has been historically used to estimate the material's pitting susceptibility.

Images of the morphology of the exposed area (Fig. 2c) show that a single, shallow pit formed during the measurement that spanned a wide diameter of $120 \mu \mathrm{m}$. The minimal penetration depth into the material indicates its ability to repassivate to avoid the formation of a perpetuating pit. Interestingly, an inclusion was found in the middle of the pit (inset in Fig. 2c). The pit morphology surrounds the inclusions as though stemming from that specific site. Smaller and deeper pits also formed adjacent of the inclusion, indicating the formation of stable penetrative pitting. Localized corrosion was only observed around pure TiN inclusions, whereas inclusions with an oxide nucleation site (Fig. 2d) showed some corrosion damage but were overall stable during the accelerated corrosion tests. The leaf-like pattern may stem from corrosion being accelerated under the physical passive film due to the corrosion inducing a steep $\mathrm{pH}$ gradient isolated from bulk solution.

Corrosion behavior of SS 444 in etching solution. Chemical depassivation was attempted using the G5-14 ASTM standard. ${ }^{25}$ The measured $E_{\text {corr }}$ was slightly more negative at $-0.22 \mathrm{~V}$ vs. SCE and the $j_{\text {lim }}$ increased to $1 \mu \mathrm{A} / \mathrm{cm}^{2}$. This $j_{\text {lim }}$ is twice the value measured in neutral $3.5 \mathrm{wt} \% \mathrm{NaCl}$, demonstrating an increase in activity at a lower pH (Fig. 3a). This may be attributed to the solubility of the passive film under acidic conditions. ${ }^{26}$ Despite the destabilization of the passive film, the current remained diffusion limited until reaching a lower transpassive region at $0.8 \mathrm{~V}$ vs. SCE. No observable pits were formed on the surface of the material prior to PDP measurements in just acidic conditions due to either the uniform destabilization of the passive film and hence no localized corrosion, or the lack of chloride ions in solution. ${ }^{6}$

The effect of lowering the stability of the passive film and the presence of chloride ions on the material's localized corrosion initiation sites was investigated in a $0.5 \mathrm{M} \mathrm{KCl}$ and $0.5 \mathrm{M} \mathrm{HCl}$ etching solution. The active to passive behavior classically reported for PDP measurements of SS was observed in the etching solution as seen in Fig. 3a. The success of this experiment can be observed with the naked eye, as the entirety of the 

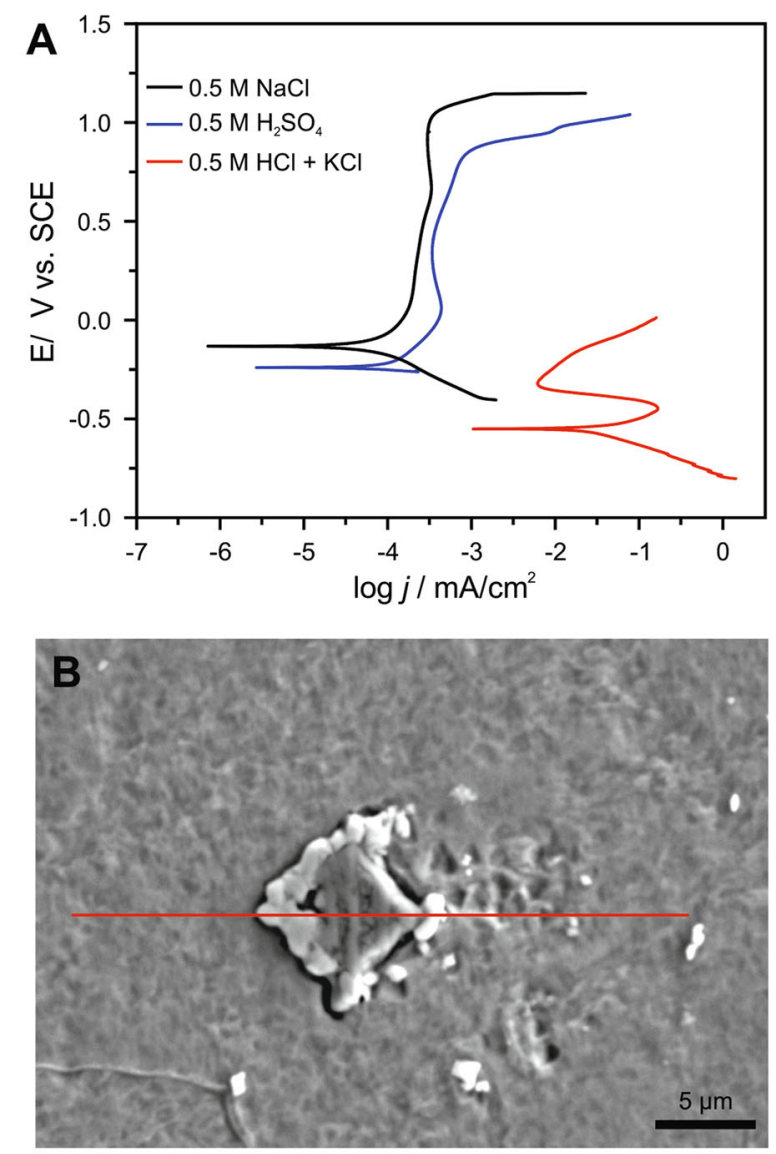

C

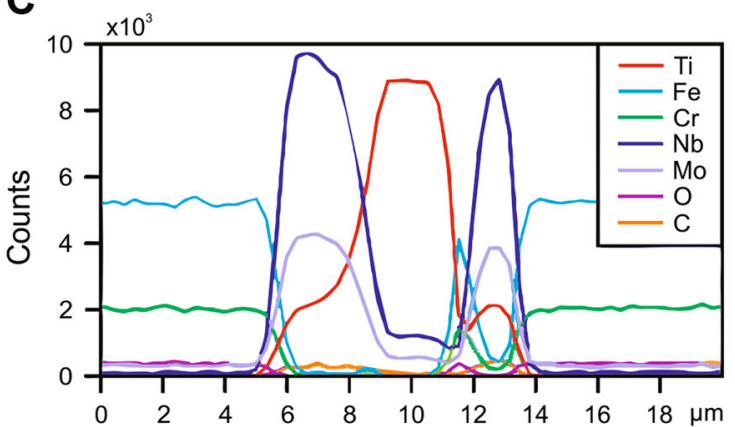

Fig. 3 a Examples of PDP measurements of polished SS 444 in $0.5 \mathrm{M}$ $\mathrm{H}_{2} \mathrm{SO}_{4}$ and etching solution as described in the G5/61 ASTM standards. A PDP measurement in $0.5 \mathrm{M} \mathrm{NaCl}$ is included for comparison (black curve). The material shows passivity in sulfuric acid (blue curve) and active/passive behavior in the etching solution (red curve) indicating successful chemical depassivation. b A SEM image of the resulting localized corrosion formed ex situ after a PDP measurement in the etching solution, showing the formation of a secondary phase (brighter in contrast) surrounding the inclusion. c EDX linescan across the TiN inclusion and secondary phase revealing the local richness in $\mathrm{Mo}$ and $\mathrm{Nb}$

exposed sample corrodes uniformly and produces a visible interface between polished and etched metal (SI Figure S8). This depassivation resulted in a more active $E_{\text {corr }}$ of $-0.508 \pm 0.12 \mathrm{~V}$ vs. SCE and much larger current densities measured, with a significantly lower breakdown potential observed in comparison to what is measured in Fig. $2 b$, corroborating a recent report of super austenitic SS. ${ }^{27}$ The shift to more negative potentials can be associated to the increase in $\mathrm{Cr}$ dissolution and the change in cathodic reaction in acidic media.
The analysis of the metal's surface after polarization in the etching solution via SEM/EDX revealed the local attack of the inclusions (Fig. 3b, c). The PDP reveals that the passive film's stability was compromised, exposing the metal matrix, importantly including areas adjacent to the electrically conductive inclusions. The observation of small $\sim 0.5 \mu \mathrm{m}$ diameter pits adjacent to every inclusion indicates a micro galvanic couple between the inclusion and the surrounding metal matrix.

A secondary phase forms at the interface between the inclusion and the adjacent metal matrix, forming a boundary of $1 \mu \mathrm{m}$ in thickness. EDX showed that the product is rich in Nb, C, and Mo, suggesting that these alloying elements play a role in resisting localized corrosion by locally segregating from the Ti-rich phase with $C$ to form a boundary to prevent exposing active material between the matrix and the inclusion. Alloying SS with Mo has been known to enhance resistance against localized corrosion, ${ }^{28,29}$ however this work provides evidence of the local precipitation of the element at vulnerable sites after accelerated corrosion, eluding how the element may inhibit localized corrosion for SS.

\section{Mapping localized surface reactivity using SECM}

From the ex situ analysis of the specimens surfaces after PDP measurements via SEM/EDX, it is clear that the Ti-rich inclusions act as corrosion initiation sites. In order to probe these differences in local reactivity prior to corrosion, SECM feedback mode was employed. A schematic and a brief description of the experimental setup of SECM can be found in the SI (SI Figure S3A). A carbon microelectrode (C-ME) tip size smaller than the investigated inclusions was selected for optimal spatial resolution (Fig. 4b). All C-MEs were characterized by cyclic voltammetry before and after all SECM measurements to ensure a high quality electrode and redox mediator stability (SI Figure S3B).

The nature of the current measured in feedback mode is from the ability of the redox mediator to regenerate at the substrate's surface and be collected at the C-ME's tip to form a feedback loop. SECM current images show local hot spots where the flux from the regeneration of redox mediator is higher than the surrounding substrate. When compared with SEM images (Fig. 4C), the hotspots can be attributed to the conductive inclusions. SECM measurements performed over the same area after $10 \mathrm{~min}$ and $3 \mathrm{~h}$ immersion in the redox mediator/supporting electrolyte show a negligible difference in the measured current over both the passive film and the conductive inclusions. This confirms that the redox mediator is stable in the presence of the SS 444 substrate and that the inclusions will not passivate even after long periods of continuous exposure (SI Figure S4). The higher current measured over the inclusions indicates an increase in kinetic rate constant of the redox mediator over the conductive features suggesting the formation of micro galvanic coupling between the inclusion and surrounding metal matrix. The enhancement of reactivity at the inclusions and their constant exposure to the electrolyte remaining unpassivated link such Ti-rich inclusions to initiating localized corrosion.

Quantitative extraction of local reactivity by finite element simulations

The evidence that the TiN inclusions are more conductive than the passivated metal matrix raises the desire to quantify the local kinetic rate constant of the redox mediator at the heterogeneous substrate. The C-ME was positioned above the hotspot (inset of Fig. $5 \mathrm{c}$ ) and a probe approach curve (PAC) was performed to obtain a quantitative measurement of the inclusion's reactivity. The approach curve to the unbiased substrate showed almost pure positive feedback indicating that the inclusion is conductive, acting as a local cathodic site with respect to the surrounding metal matrix. The approach curves obtained over the passive film display almost pure negative feedback confirming the insulating 

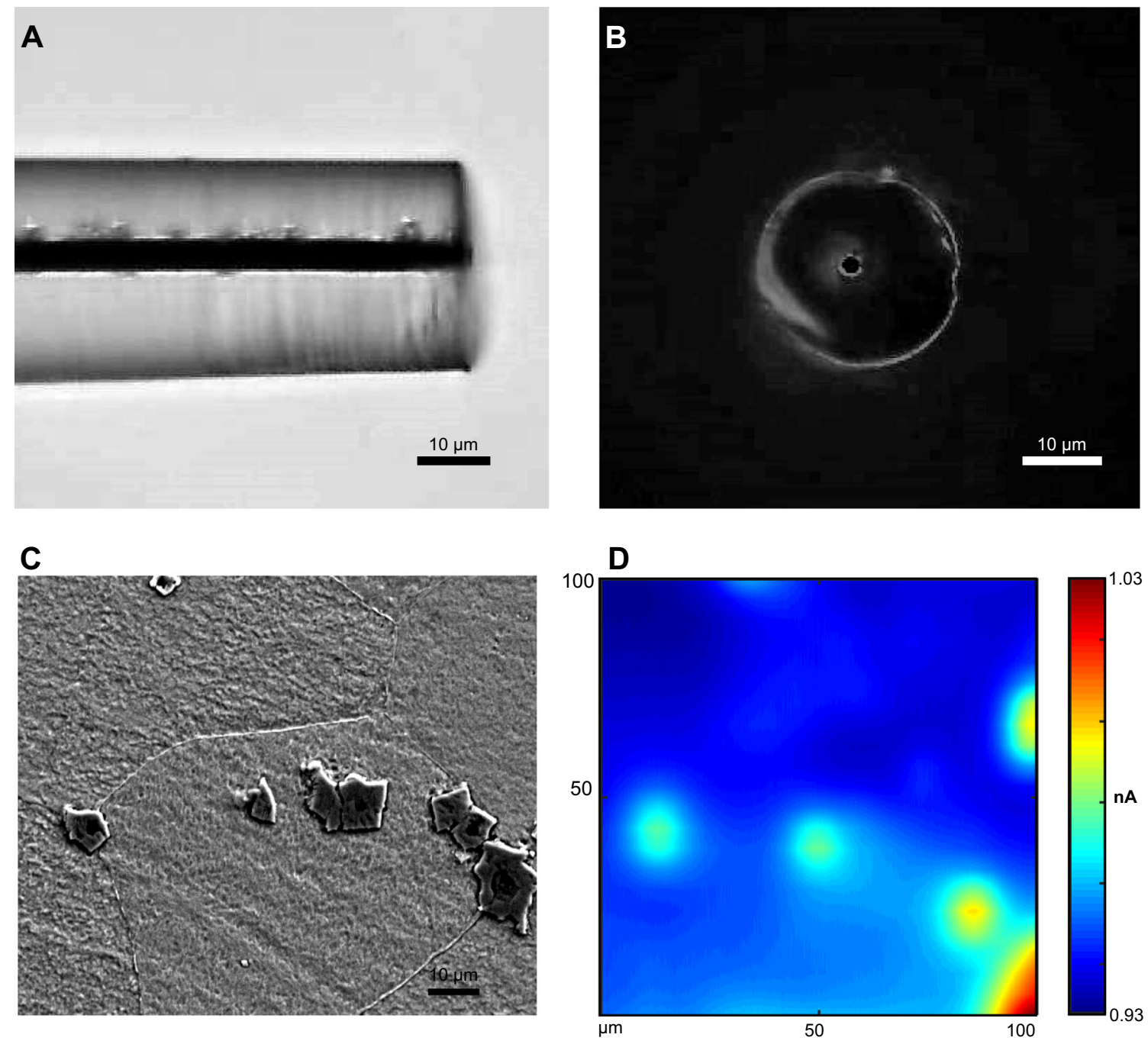

Fig. 4 Micrographs of the C-ME (radius $=2.35 \mu \mathrm{m}$ ) fabricated in house and from the a side and $\mathbf{b}$ top view. SEM image (c) and SECM (d) current image map of similar sites on the substrate. The local hotspots detected correspond to the conductive inclusions within the materials microstructure

behavior of the non-polarized passive layer. ${ }^{30}$ The PAC measurements were repeated over different inclusions and passivated areas to obtain a standard deviation and associated error of local reactivity across the SS 444 (SI Figure S12). Analytical approximations have been developed and are frequently used to extract the local heterogeneous rate constant from a PAC, ${ }^{31}$ but the majority of these assume a uniformly reacting substrate. 2D-axisymmetric finite element simulations have previously been employed to study conductive inclusions in otherwise insulating substrates for $\mathrm{Al}$ and $\mathrm{Ti}$ alloys, ${ }^{32,33}$ but the high symmetry requirements make these entirely unsuitable for highly heterogeneous systems such as those here presented. Therefore, a full 3D model (Fig. 5a) was built to study this system, the full details of which can be found in the Supporting Information. Approach curves were simulated by calculating the steady-state reaction rate for a series of tipsubstrate distances according to the Nernst-Planck equation (Equation 4) under conditions of no convection or migration:

$\nabla \cdot\left(-D_{i} \nabla c_{i}\right)=R_{i}$

where $D_{\mathrm{i}}$ is the diffusion coefficient, $c_{\mathrm{i}}$ the concentration, and $R_{\mathrm{i}}$ the reaction rate of species $i$. Species are consumed and produced in accordance with the reactions at the surface described by
Equation 5:

$-\mathbf{n} \cdot \mathbf{N}_{i}=N_{0 j}$

where $\mathbf{n}$ is the normal vector, $\mathbf{N}_{\mathrm{i}}$ is the flux of species $i$ associated with mass transport, and $N_{0, i}$ is the flux of species $i$ associated with a chemical reaction at the surface. The reactions occurring at the inclusion are described by Equation 6:

$N_{0, c_{o x}}=-N_{0, c_{\text {red }}}=-k_{\text {in }} c_{o x}$

where $k_{\text {in }}$ is the rate constant at the inclusion. Accurate model behavior was validated through the comparison of simulated PAC over a uniformly reacting substrate to the traditional analytical approximation (SI Figure S11). Using the dimensions of the probe and inclusion extracted from microscopy techniques, a series of approach curves with varying $k_{\text {in }}$ was generated and the best fit determined statistically by the lowest average percentage difference over the length of the curve. The reactivity of the passive film was determined first, assuming a uniform substrate. This was then used to determine the reactivity of the inclusion, assuming a square conductive feature in an otherwise uniform passive film (Fig. 5b). This analysis was done on the three PAC experiments performed to obtain local rate constants of $k_{\text {in }}=2.8 \pm$ $0.1 \mathrm{~cm} / \mathrm{s}$ and $k_{\mathrm{p}}=0.19 \pm 0.01 \mathrm{~cm} / \mathrm{s}$ (Fig. $5 \mathrm{c}$ ), with the local rate constant over the inclusion being an order of magnitude faster 

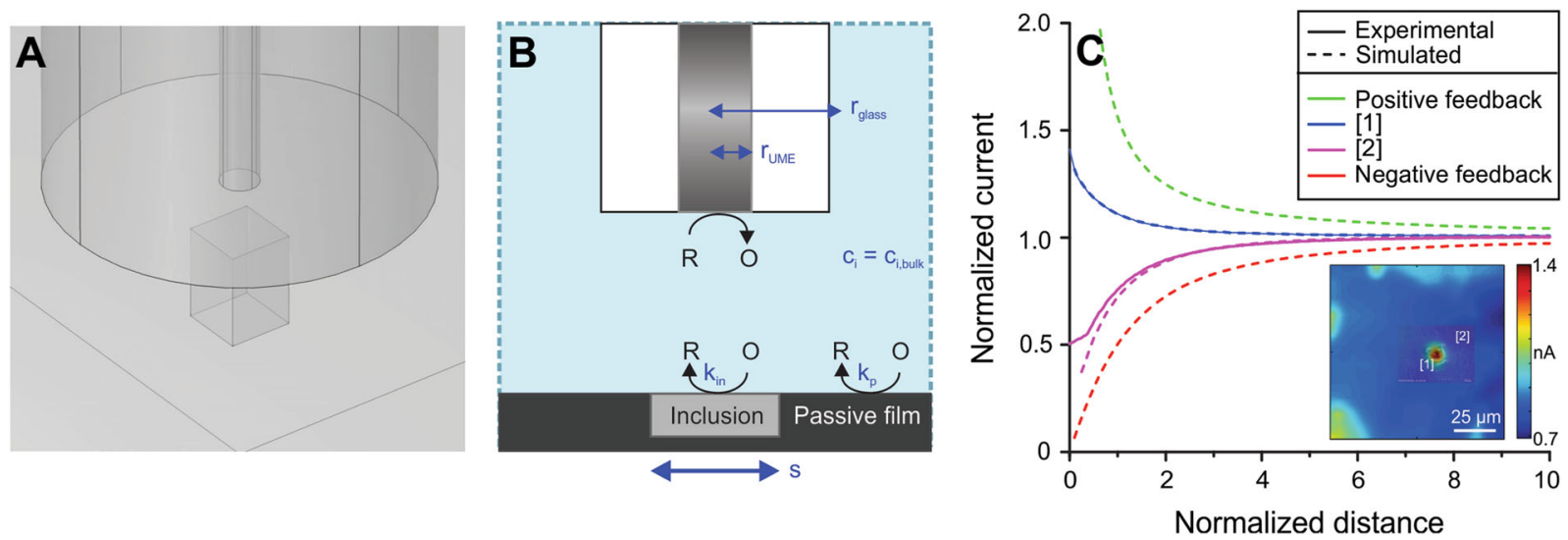

Fig. 5 a 3D model geometry used for the finite element simulations. $\mathbf{b}$ Schematic of the reacting surfaces and boundary conditions employed in the presence of an inclusion. The radius of glass sheath $\left(r_{\text {glass }}\right)$, radius of microelectrode $\left(r_{\mathrm{UME}}\right)$ and diameter of inclusion $(s)$ were selected based on experimental parameters, with $r_{\mathrm{UME}}=2.35 \mu \mathrm{m}, r_{\text {glass }}=22.56 \mu \mathrm{m}$, and $s=8 \mu \mathrm{m}$. c Extraction of local rate constants from PAC performed over a TiN inclusion [1] and passivated metal matrix [2]. Pure positive and negative feedback are shown for comparison purposes. The extracted rate constants are $k_{1}=2.0 \pm 0.1 \mathrm{~cm} / \mathrm{s}$ and $k_{2}=0.19 \pm 0.01 \mathrm{~cm} / \mathrm{s}$

than over the passive film. This enhanced rate constant is consistent with enhanced reactivity at the surface in that location, as is expected for an initiation site for pitting corrosion.

\section{DISCUSSION}

SECM measurements over the heterogeneous SS 444 substrate not only revealed the enhanced reactivity of the inclusions in comparison to the passivated $\mathrm{Fe}-\mathrm{Cr}$ metal matrix, but also suggest a lack of passive film over the inclusions entirely as proven to be true for previously described MnS inclusions. ${ }^{34}$ In a corrosive environment, localized corrosion is more likely to occur at these points of vulnerability. TiN is a popular material for corrosion resistant coatings due to its noble $E_{\text {corr }}(-0.016 \mathrm{~V}$ vs. SCE reported by Zuo et al. in artificial saliva). ${ }^{14}$ This value is more noble than that reported for SS 444 here, suggesting that TiN rich inclusions can form a galvanic couple with the Fe metal matrix acting as the anode. This galvanic couple becomes predominant as the protective passive film is weakened. The stability of the inclusions containing a $\mathrm{Mg} / \mathrm{Al}$ oxide core during corrosion measurements are not found to be sites of localized attack because the active oxide core preferentially dissolves, leaving a conductive yet broken TiN shell that remains stable and resistant to further degradation. The loss of the core disrupts the cathode's structure, which decreases its ability to galvanically couple to the metal matrix such that these nucleated inclusions are considered stable under the stagnant conditions described here. This is a marked contrast from MnS inclusions observed for austenitic SSs, which dissolve readily. ${ }^{7}$ Despite such $\mathrm{Mg} / \mathrm{Al}$ oxide core inclusion's stability in this study, their role in material fatigue during wear testing has been documented. ${ }^{16}$

The role these inclusions play in localized corrosion is an unintentional consequence of the presence of $\mathrm{Ti}$ in the alloy, which is intentionally added to ferritic SS to inhibit $\mathrm{CrC}$ precipitation and decrease IGC. ${ }^{3}$ This work shows that they are effective at inhibiting sensitization as the grain boundaries are free of the micron-sized inclusions reported here and instead are distributed amongst large grain faces. Undesirable $\mathrm{CrC}$ precipitates were not observed within the microstructure of the studied $\mathrm{SS}$. The other stabilizing agent, $\mathrm{Nb}$, was observed to mostly precipitate out with $C$ at the interface between the inclusion and the surrounding metal matrix, acting as a boundary and hence protecting the material from further corroding. The stochastic distribution of the conductive inclusions (Fig. 4c, d) may lower the material's susceptibility to localized corrosion since spacing between the resulting pits inhibits the amalgamation of the localized corrosion. In contrast, a material that undergoes IGC may be more susceptible to localized corrosion due to the sensitization of $\mathrm{CrC}$ precipitates, where nearby pits are able to merge to form large active pits that can propagate through the material at a faster rate.

The addition of Mo to SS alloys has proven to be beneficial to the material's resistance against localized corrosion. This has previously been attributed to its participation in the creation of a robust and protective passive film. ${ }^{28,35}$ This hypothesis is counter intuitive however, because pure Mo is not known to form a protective physical passive film. ${ }^{36}$ Figure $3 \mathrm{~b}$, c shows the local formation of Mo-rich secondary phase around the inclusions after accelerated corrosion tests, segregating between those and the metal matrix found within the same phase as the stabilizing agent $\mathrm{Nb}$. The SEM/EDX data collected here both prior to polishing and after corrosion testing enlightens corrosion research on Mo's true contribution to the materials overall localized corrosion resistance.

The $E_{\text {corr }}$ measured in this work (Fig. 2) is more active than a previously reported value for the same material in high saline concentration by Marques et al. of $-0.0025 \mathrm{~V}$ vs. SCE. ${ }^{20}$ This discrepancy may be due to the small differences in elemental composition, or rather the extensive immersion time of 2 days, where the material has had a longer period of time to passivate before carrying out the PDP measurement. The $j_{\text {lim }}$ measured here and that reported previously ${ }^{23}$ is less than the corrosion current density reported by Bitondo et al. of $1.1 \pm 0.7 \mu \mathrm{A} / \mathrm{cm}^{2}$ for annealed polished SS samples. ${ }^{19}$ It should be noted however that differences in experimental methodology such as using a faster scan rate, small electrolyte volumes, and possible differences in data analysis (not specified in referenced work) may lead to a very different calculated $j_{\text {corr }}$.

A transpassive region was observed in both neutral 3.5 wt $\%$ $\mathrm{NaCl}$ and $0.5 \mathrm{M} \mathrm{H}_{2} \mathrm{SO}_{4}$ electrolytes. The increase in current density characteristic of this region can be attributed to either the oxidative dissolution of the passive film ${ }^{37}$ or the competing reaction of oxygen evolution, which can interfere with the transpassive behavior during the PDP measurement. Since the damage to the passive film and observation of localized corrosion on naturally passivated samples was minimal, it is inferred here that the increased current in the transpassive region is first due to the onset of oxygen evolution before the breakage of the passive film. Similar behavior was documented for samples of SS 444 immersed for a prolonged period of time ${ }^{20}$ or immersed in more diluted saline electrolytes. ${ }^{18,19}$ The lack of premature pitting before reaching the transpassive region proves the material's low susceptibility to pitting corrosion and highlights the impressive 
corrosion resistance of the material as predicted by suppliers. However, this study has highlighted the potential of combining macro and micro electrochemical techniques to gain mechanistic insight on how a material will eventually fail over a lab-friendly time scale.

After just 7 days of PDP measurements and immersion in $3.5 \mathrm{wt}$ $\%$ solution, the material shows signs of localized corrosion adjacent the conductive inclusions. One could suspect that if left for long enough, the inclusions may expel from the material's microstructure due to localized corrosion. Although no detachment of the inclusions was observed in this study, such hypothesis is important to keep in mind when studying the material's microstructure after long time immersion failure in future field studies. The micro crevice and pitting corrosion patterns observed after the electrochemical depassivation experiments suggests that the exposure of active material first occurs between inclusions and the metal matrix and then spreads outwards underneath the stable protective passive film. The observation of micro pits located adjacent to every conductive inclusion during the PDP experiments in the etching solution at potentials more negative than the measured breakdown potential enforces their role in localized corrosion. This is in agreement with potentiostatic measurements reported recently for a similar Ti stabilized alloy. ${ }^{38}$

The use of the 3D finite element model created for accurately comparing experimental PAC to analytical approximations (Fig. 5) calculated an order of magnitude in difference in reactivity for the inclusions versus the passivated metal matrix. Similar 2D models have been reported for other materials such as $\mathrm{Ti}^{3} 7^{33}$ and $\mathrm{Al} / \mathrm{Cu}$ alloys $^{32}$ but have never been used to explore electrically conductive inclusions on SS surfaces and further link such features to localized corrosion attacks. The difference in behavior between TiN inclusions and previously reported MnS inclusions for austenitic steels yields differences in their localized corrosion behavior. This corrosion resistant steel has potential applications in the power industry and so understanding the failure mechanism of these Ti-stabilized ferritic SS is critical to their planned use. By being able to quantify local reactivity of the materials microstructure and link observations to the materials corrosion properties, the work presented here will bench mark the characterization methods needed to investigate SS's corrosion behavior using macro and micro electrochemical techniques.

We have found that the $\mathrm{Ti}$ added as a stabilizing agent to enhance the IGC resistance of ferritic SS ultimately plays a significant role in its localized corrosion behavior, with the Ti-rich inclusions formed acting as the initiation sites for localized corrosion. Ti does have a beneficial effect on the bulk corrosion properties of the material; with the SS 444 samples studied demonstrating extreme corrosion resistance and no premature pitting during the accelerated corrosion environment of a PDP measurement. However, combined PDP and immersion testing revealed that this material eventually undergoes localized attack, threatening its structural integrity.

Two methods were employed to destabilize the protective passive film in order to study the effect of the underlying microstructure on localized corrosion. SEM/EDX investigation of the specimens after depassivation revealed that the Ti-rich inclusions act as initiation sites. The alloying elements Mo and $\mathrm{Nb}$ have been linked to segregation at vulnerable sites at the interface between the conductive inclusions and the metal matrix. This formation of a secondary phase seems to be protective in nature and therefore increases the material's resistance towards degradation. The local reactivity of the heterogeneous substrate was measured using the microscopy techniques, SEM and SECM, to quantify the difference in reactivity across the materials surface. The 3D finite element model implemented allowed for quantitative study of the local difference in reactivity between the conductive inclusions and passivated ferrous metal.
This work demonstrates the power of pairing microscopy techniques in order to investigate relevant industrial material and will act as an ideal model system when investigating more complex systems in the future. Based on the formation and characterization of the secondary phase formed after accelerated corrosion, alloying Ti alloyed metals with elements such as Mo and $\mathrm{Nb}$ should also be encouraged to minimize the propagation of localized corrosion at vulnerable sites.

\section{METHODS}

Materials and sample preparation

Standard polishing procedure. AISI grade SS 444 was produced by ArcelorMittal. All specimens were sectioned from 4-mm thick plates into $2 \mathrm{~cm} \times 2 \mathrm{~cm}$ samples using an abrasive cutter (abrasiMet 250, Buehler, USA). Samples were fixed in cold mounting epoxy (Epofix-Struers). The steel was ground using a series of SiC papers $(800,1200$ and 4000 grit, Struers, Canada) and polished using a $0.05 \mu \mathrm{m}$ aluminum oxide suspension and a MD Chem cloth (Struers, Canada) to obtain a mirror-like surface. All grinding and polishing procedures were carried out using a TegraPol-25 polishing wheel and an automated TegraForce-5 polishing arm (Struers, USA). All samples were sonicated in anhydrous ethanol for $2 \mathrm{~min}$ to remove any alumina residue, and then dried under a stream of air.

\section{Instrumentation}

SEM/EDX analysis. All SEM images were obtained using a Hitachi SU3500 variable pressure scanning electron microscope equipped with XEDS (Oxford, Inca, Silicon drift detector) for micro-elemental composition determination of inclusions and secondary phases. Topographic information was obtained by collecting the secondary electron signal produced from the specimen itself while elemental composition information was explored via detection of back-scattered electrons stemming from the incident beam and $\mathrm{x}$-ray emissions.

PDP measurements. All PDP measurements were performed using a multi-channel VSP-300 potentiostat (BioLogic Science Instruments, USA) with $1 \mu \mathrm{V}$ resolution. Experimental parameters for PDP measurements were based on the relevant ASTM test method. ${ }^{39}$ A standard bench top corrosion cell (K0235 Flat Cell, Princeton Applied Research, AMETEK ${ }^{\circ}$ Scientific Instruments) with an isolated area of $1 \mathrm{~cm}^{2}$ was used as the main corrosion cell for all PDP, a schematic of which is given in the SI. A calibrated saturated calomel electrode (SCE) and platinum mesh were used as the reference and counter electrodes respectively.

In order to minimize solution resistance and to simulate severe corrosion conditions, $3.5 \mathrm{wt} \% \mathrm{NaCl}$ electrolyte was chosen as the main test solution for immersion testing and standard electrochemical measurements. Additional information in more aggressive electrolytes was determined in a $0.5 \mathrm{M} \mathrm{H}_{2} \mathrm{SO}_{4}$ solution as described in the G5 ASTM standard, ${ }^{25}$ and etching solution composed of $0.5 \mathrm{M} \mathrm{HCl}$ and $0.5 \mathrm{M} \mathrm{KCl}$. All reagents including $\mathrm{NaCl}, \mathrm{KCl}, \mathrm{HCl}$, and $\mathrm{H}_{2} \mathrm{SO}_{4}$ (>99\% purity) were purchased from Sigma-Aldrich. All solutions were made using deionized water from a Milli$\mathrm{Q}^{\circ}$ water purification system $(18.2 \mathrm{M} \Omega \mathrm{cm}$ resistivity). All measurements were performed using a freshly polished and cleaned specimen after the sample had been immersed in the aerated test solution for $1 \mathrm{~h}$. A Faraday cage and a vibration isolation table were used during all PDP measurements. All polarization tests were carried out for at least three replicates to ensure reproducibility of the material's corrosion behavior.

Carbon microelectrode fabrication. All C-ME characterization and SECM were performed with an EIProScan 3 system (HEKA, Germany; bipotentiostat model PG340). The prepared SS substrate was probed using a $4.7 \mu \mathrm{m}$ diameter C-ME, which was fabricated following an established protocol, ${ }^{40}$ reproduced in the SI.

SECM feedback mode measurements. A $1 \mathrm{mM}$ FcMeOH (Acros Organic, New Jersey, USA) in $0.1 \mathrm{M} \mathrm{KCl}$ supporting electrolyte (ACP, Montreal, Quebec) aqueous solution was used for all SECM measurements. The C-ME tip was polarized at $350 \mathrm{mV}$ vs. SCE and the exact tip-substrate calibrated by first making contact with the surface, then retracting the tip $200 \mu \mathrm{m}$. The tip was then retracted and positioned $5 \mu \mathrm{m}$ above the substrate's surface. The C-ME was rastered across the sample at $10 \mu \mathrm{m} / \mathrm{s}$ in order to collect the current map of the substrate. PAC were performed at a $1 \mu \mathrm{m} / \mathrm{s}$ approach speed. All measurements were performed in triplicate. 
Data availability

The data sets generated during and/or analyzed during the current study are available from the corresponding author upon reasonable request.

\section{ACKNOWLEDGEMENTS}

The work performed at McGill was supported financially by NSERC CRD 242399 and Hydro Quebec. Authors would also like to acknowledge llias Halimi for ICP measurements and Nicholas Payne for insightful discussion.

\section{AUTHOR CONTRIBUTIONS}

S.M.G performed all experiments and was the majority contributor to the data analysis and manuscript preparation. L.I.S. performed the finite element modeling. S. C.P., R.L., and R.S. provided discussion and manuscript feedback.

\section{ADDITIONAL INFORMATION}

Supplementary information accompanies the paper on the npj Materials Degradation website (https://doi.org/10.1038/s41529-018-0026-5).

Competing interests: The authors declare no competing financial interests.

Publisher's note: Springer Nature remains neutral with regard to jurisdictional claims in published maps and institutional affiliations.

\section{REFERENCES}

1. Burkert, A., Lehmann, J., Burkert, A., Mietz, J. \& Gümpel, P. Technical and economical stainless steel alternatives for civil engineering applications. Mater. Corros. 65, 1080-1095 (2014).

2. Gwinner, B. et al. Towards a reliable determination of the intergranular corrosion rate of austenitic stainless steel in oxidizing media. Corros. Sci. 107, 60-75 (2016).

3. Pardo, A. et al. Influence of $\mathrm{Ti}, \mathrm{C}$ and $\mathrm{N}$ concentration on the intergranular corrosion behaviour of AISI 316Ti and 321 stainless steels. Acta Mater. 55, 2239-2251 (2007).

4. Yin, X. et al. Formation of inclusions in Ti-stabilized $17 \mathrm{Cr}$ austenitic stainless steel. Metall. Mater. Trans. B 47, 3274-3284 (2016).

5. Huang, X., Wang, D. \& Yang, Y. Effect of precipitation on intergranular corrosion resistance of 430 ferritic stainless steel. J. Iron Steel Res. Int. 22, 1062-1068 (2015).

6. Soltis, J. Passivity breakdown, pit initiation and propagation of pits in metallic materials-review. Corros. Sci. 90, 5-22 (2015).

7. Pardo, A. et al. Pitting corrosion behaviour of austenitic stainless steels-combining effects of Mn and Mo additions. Corros. Sci. 50, 1796-1806 (2008).

8. Ma, J. et al. Anisotropic 3D growth of corrosion pits initiated at MnS inclusions for A537 steel during corrosion fatigue. Corros. Sci. 52, 2867-2877 (2010).

9. Stewart, J. \& Williams, D. E. The initiation of pitting corrosion on austenitic stainless steel: on the role and importance of sulphide inclusions. Corros. Sci. 33, 457-474 (1992).

10. Jun, J., Holguin, K. \& Frankel, G. S. Pitting corrosion of very clean type 304 stainless steel. Corrosion 70, 146-155 (2014).

11. Williams, D. E., Mohiuddin, T. F. \& Zhu, Y. Y. Elucidation of a trigger mechanism for pitting corrosion of stainless steels using submicron resolution scanning electrochemical and photoelectrochemical microscopy. J. Electrochem. Soc. 145, 2664 (1998).

12. Muto, I., Izumiyama, Y. \& Hara, N. Microelectrochemical measurements of dissolution of MnS inclusions and morphological observation of metastable and stable pitting on stainless steel. J. Electrochem. Soc. 154, C439 (2007).

13. Silva, C. C. et al. Microstructural characterization of the HAZ in AISI 444 ferritic stainless steel welds. Mater. Charact. 59, 528-533 (2008).

14. Zuo, J. et al. TiN coated stainless steel bracket: Tribological, corrosion resistance, biocompatibility and mechanical performance. Surf. Coat. Technol. 277, 227-233 (2015).

15. Tan, J. et al. Role of TiN inclusion on corrosion fatigue behavior of Alloy 690 steam generator tubes in borated and lithiated high temperature water. Corros. Sci. 88, 349-359 (2014).

16. Meng, F., Wang, J., Han, E.-H. \& Ke, W. The role of TiN inclusions in stress corrosion crack initiation for Alloy 690TT in high-temperature and high-pressure water. Corros. Sci. 52, 927-932 (2010).

17. Ha, H. Y., Park, C. J. \& Kwon, H. S. Effects of non-metallic inclusions on the initiation of pitting corrosion in $11 \% \mathrm{Cr}$ ferritic stainless steel examined by microdroplet cell. Corros. Sci. 49, 1266-1275 (2007).

18. Bellezze, T., Roventi, G., Quaranta, A. \& Fratesi, R. Improvement of pitting corrosion resistance of AISI 444 stainless steel to make it a possible substitute for AISI $304 \mathrm{~L}$ and $316 \mathrm{~L}$ in hot natural waters. Mater. Corros. 59, 727-731 (2008).
19. Bitondo, C., Bossio, A., Monetta, T., Curioni, M. \& Bellucci, F. The effect of annealing on the corrosion behaviour of 444 stainless steel for drinking water applications. Corros. Sci. 87, 6-10 (2014).

20. Marques, R. A., Rogero, S. O., Terada, M., Pieretti, E. F. \& Costa, I. Localized corrosion resistance and cytotoxicity evaluation of ferritic stainless steels for use in implantable dental devices with magnetic connections. Int. J. Electrochem. Sci. 9, 1340-1354 (2014).

21. Feliu, S., Maffiotte, C., Samaniego, A., Galván, J. C. \& Barranco, V. Effect of the chemistry and structure of the native oxide surface film on the corrosion properties of commercial AZ31 and AZ61 alloys. Appl. Surf. Sci. 257, 8558-8568 (2011).

22. Sabioni, A. C. S. et al. lon diffusion study in the oxide layers due to oxidation of AISI 439 ferritic stainless steel. Oxid. Met. 81, 407-419 (2014).

23. Stephens, L. I. et al. Development of a model for experimental data treatment of diffusion and activation limited polarization curves for magnesium and steel alloys. J. Electrochem. Soc. 164, E3576-E3582 (2017).

24. Shibata, T. Stochastic approach to the effect of alloying elements on the pitting resistance of ferritic stainless steels. Trans. Iron Steel Inst. Jpn. 23, 785-788 (1983).

25. ASTM G5-14, Standard Reference Test Method for Making Potentiodynamic Anodic Polarization Measurements, (ASTM International, West Conshohocken, PA, 2014) http://www.astm.org.

26. Ishitsuka, T. \& Nose, K. Stability of protective oxide films in waste incineration environment-solubility measurement of oxides in molten chlorides. Corros. Sci. 44, 247-263 (2002).

27. Kim, S. J., Hong, S. G. \& Oh, M. Effect of metallurgical factors on the pitting corrosion behavior of super austenitic stainless steel weld in an acidic chloride environment. J. Mater. Res. 32, 1343-1350 (2017).

28. Kaneko, M. \& Isaacs, H. S. Effects of molybdenum on the pitting of ferritic- and austenitic-stainless steels in bromide and chloride solutions. Corros. Sci. 44, 1825-1834 (2002)

29. Jargelius-Pettersson, R. F. A. \& Pound, B. G. Examination of the role of molybdenum in passivation of stainless steels using AC impedance spectroscopy. J. Electrochem. Soc. 145, 1462-1469 (1998).

30. Sunseri, C. Photocurrent spectroscopic investigations of passive films on chromium. J. Electrochem. Soc. 137, 2411 (1990).

31. Lefrou, C. \& Cornut, R. Analytical expressions for quantitative scanning electrochemical microscopy (SECM). Chemphyschem 11, 547-556 (2010).

32. Jensen, M. B., Guerard, A., Tallman, D. E. \& Bierwagen, G. P. Studies of electron transfer at aluminum alloy surfaces by scanning electrochemical microscopy. $J$. Electrochem. Soc. 155, C324-C332 (2008).

33. Zhu, R., Qin, Z., Noël, J. J., Shoesmith, D. W. \& Ding, Z. Analyzing the influence of alloying elements and impurities on the localized reactivity of titanium grade-7 by scanning electrochemical microscopy. Anal. Chem. 80, 1437-1447 (2008).

34. Ryan, M. P., Williams, D. E., Chater, R. J., Hutton, B. M. \& McPhail, D. S. Why stainless steel corrodes. Nature 415, 770-774 (2002).

35. Montemor, M. F., Simões, Amp, Ferreira, M. G. S. \& Belo, M. D. C. The role of Mo in the chemical composition and semiconductive behaviour of oxide films formed on stainless steels. Corros. Sci. 41, 17-34 (1999).

36. Brox, B., Yi-Hua, W. \& Olefjord, I. Electrochemical and surface analyses of Mo (100) single crystal polarized in $0.5 \mathrm{M} \mathrm{H}_{2} \mathrm{SO}_{4}$. J. Electrochem. Soc. 135, 2184-2187 (1988).

37. Macdonald, D. D. Passivity-The key to our metals-based civilization. Pure Appl. Chem. 71, 951-978 (1999).

38. Souza, J. S., de, Oliveira, L. A., de, Sayeg, I. J. \& Antunes, R. A.Electrochemical study of the AISI 409 ferritic stainless steel: passive film stability and pitting nucleation and growth. Mater. Res. 20, 1669-1680 (2017).

39. ASTM G61-86, Standard Test Method for Conducting Cyclic Potentiodynamic Polarization Measurements for Localized Corrosion Susceptibility of Iron-, Nickel-, or Cobalt-Based Alloys, (ASTM International, West Conshohocken, PA, 2014) http://www.astm.org.

40. Danis, L., Polcari, D., Kwan, A., Gateman, S. M. \& Mauzeroll, J. Fabrication of carbon, gold, platinum, silver, and mercury ultramicroelectrodes with controlled geometry. Anal. Chem. 87, 2565-2569 (2015).

Open Access This article is licensed under a Creative Commons Attribution 4.0 International License, which permits use, sharing, adaptation, distribution and reproduction in any medium or format, as long as you give appropriate credit to the original author(s) and the source, provide a link to the Creative Commons license, and indicate if changes were made. The images or other third party material in this article are included in the article's Creative Commons license, unless indicated otherwise in a credit line to the material. If material is not included in the article's Creative Commons license and your intended use is not permitted by statutory regulation or exceeds the permitted use, you will need to obtain permission directly from the copyright holder. To view a copy of this license, visit http://creativecommons. org/licenses/by/4.0/.

(c) The Author(s) 2018 